\title{
Cervical spine movement during intubation
}

\author{
Amlan Swain, Seelora Sahu, Bhanu P. Swain
}

\begin{abstract}
There have been growing concerns following documented instances of neurological deterioration in patients with cervical spine injury as a result of intubation. A significant body of evidence has since evolved with the primary objective of ascertaining the safest way of securing the endotracheal tube in patients with suspected and proven cervical injury. The search for a mode of intubation producing the least movement at the cervical spine is an ongoing process and is limited by logistic and ethical issues. The ensuing review is an attempt to review available evidence on cervical movements during intubation and to comprehensively outline the movement at the cervical spine with a wide plethora of intubation aids. Literature search was sourced from digital libraries including PubMed, Medline and Google Scholar in addition to the standard textbooks of Anaesthesiology. The keywords used in literature search included 'cervical spine motion,' 'neurological deterioration,' 'intubation biomechanics,' 'direct laryngoscopy,' 'flexible fibreoptic intubation,' 'video laryngoscopes' and 'craniocervical motion.' The scientific information in this review is expected to assist neuroanaesthesiologists for planning airway management in patients with neurological injury as well as to direct further research into this topic which has significant clinical and patient safety implications.
\end{abstract}

Key words: Cervical spine movement, fibreoptic bronchoscopy, intubation, laryngoscopy

\section{INTRODUCTION}

Endotracheal intubation is established as the gold standard for securance of the airway. ${ }^{[1]}$ It is also a common procedure in clinical practice and its use varies from the administration of general anaesthesia to the amelioration of ventilatory perturbations throughout the hospital, right from the emergency department to the critical care setups. ${ }^{[1]}$ Research on cervical motion during intubation started at the end of the last century following the disturbing reports of cervical spinal cord injury sustained during intubation. ${ }^{[2,3]}$ The studies on cervical spine motion kinetics have progressed from

Department of Anaesthesia and Critical Care, Tata Main Hospital, Jamshedpur, Jharkhand, India

Address for correspondence:

Dr. Seelora Sahu, A - 36, Professional Flats A, K. S. Link Road,

B. H. Area, Kadma, Jamshedpur - 831 005, Jharkhand, India.

E-mail: seelora@gmail.com

\begin{tabular}{|l|l|}
\hline \multicolumn{2}{|c|}{ Access this article online } \\
\hline Quick Response Code: & Website: \\
\hline & www.jnaccjournal.org \\
\cline { 2 - 3 } & \\
\hline
\end{tabular}

cadaver to human participants. Extensive research has been conducted on craniocervical motion caused by a wide range of intubation aids such as various classical laryngoscopes, video laryngoscopes, supraglottic devices and flexible fibre-optic bronchoscopy (FB). The modality for capturing cervical spine motion during the various aforementioned forms of intubation has also simultaneously evolved from X-rays of the cervical spine at predefined time points to continuous cinefluoroscopy. The use of cinefluoroscopy has enabled a more precise understanding of cervical spine kinetics during the process of intubation and has also increased the probability of capturing maximal motion. The aim of this review is to present the available evidence regarding cervical spine motion with various intubation devices as well as probable future directions of research in this fledgling but exciting subject.

This is an open access article distributed under the terms of the Creative Commons Attribution-NonCommercial-ShareAlike 3.0 License, which allows others to remix, tweak, and build upon the work non-commercially, as long as the author is credited and the new creations are licensed under the identica terms.

For reprints contact: reprints@medknow.com

How to cite this article: Swain A, Sahu S, Swain BP. Cervical spine movement during intubation. J Neuroanaesthesiol Crit Care 2017; 4:S76-80. 


\section{CADAVER STUDIES}

Lennarson et al. were amongst the earliest scientists to study cervical spine motion in cadavers with intact as well as surgically modified unstable cervical spines. ${ }^{[4,5]}$ They were amongst the first scientists to quantify the degree of movement of each vertebral level at the cervical spine. They established that laryngoscopy resulted primarily in neck extension at the Oc-C5 with the greatest fraction of the movement occurring at the Oc-C1 and C1-C2 cervical vertebral levels. Lennarson et al. also investigated the immobilisation techniques such as manual in-line stabilisation (MILS) and application of axial traction with Gardner-Wells tongs and conclusively demonstrated lesser subluxation with MILS. Gerling et al. showed that Miller blade caused lesser movement in comparison to both Mc Intosh and McCoy blades while simultaneously noting that cervical collar immobilisation has the potential of aggravating existing cervical spine injuries. ${ }^{[6]}$ Donaldson et al. proved that oral intubation was associated with more movement at the cervical spine vis-a-vis nasal intubation. They also exhibited that manoeuvres such as 'chin lift' and 'jaw thrust' were responsible for as much movement of the cervical spine as the actual process of intubation itself. ${ }^{[7,8]}$ Although cadaver studies suffered from inherent limitation of not replicating cervical spine dynamics in live human participants, nonetheless they provided the first glimpses into cervical spine movement during intubation and dictated future directions on research in live participants.

\section{CERVICAL SPINE MOVEMENT IN LIVE PATIENTS}

\section{Studies with classical blades}

Sawin et al. performed a direct laryngoscopic in vivo study of cervical spine motion with continuous lateral fluoroscopy in ten patients with a Macintosh \#3 blade. It was one of the earliest studies on live patients and measured cervical spine movement at two stages, first at the pre-insertion stage when the laryngoscope was in the larynx and the second measurement was made during application of the ventral force of direct laryngoscopy. They demonstrated that the majority of movement occurred at the atlanto-occipital and atlanto-axial joints during application of ventral lifting force ${ }^{[9]}$ LeGrand et al. compared the craniocervical movement during direct laryngoscopy with the Macintosh and Miller blades using digital cinefluoroscopy images and reported significantly less cervical extension at the occiput-C1 location and decreased overall extension with the Miller blade as compared to the Macintosh blade. ${ }^{[10]}$ The difference in movement though significant in statistical terms was probably clinically insignificant because of the small difference in overall cervical spine movement between the two blades. Hastings and Wood conducted a randomised control trial in 31 patients to measure cervical spine extension with the Macintosh \#3 blade during laryngoscopy with different immobilisation techniques and found decreased cervical extension with MILS as compared to no immobilisation. ${ }^{[11]}$ Hastings et al. subsequently analysed external head extension amongst the Bullard, Macintosh and Miller laryngoscopes and reported decreased external head extension with the Bullard laryngoscope as compared to the Macintosh and Miller laryngoscopes. ${ }^{[12]}$ While head extension was measured by applying an external angle finder in all 35 patients, cervical spine measurements were obtained from radiographic images in eight patients. The eight patients who were studied radiographically had decreased cervical spine extension with the Bullard laryngoscope in comparison with the Macintosh laryngoscope. A positive of this study was a table that reported angles between adjacent cervical levels and provided baseline measurements for comparison in future studies. MacIntyre et al. observed cervical spine movement while comparing the Macintosh and McCoy laryngoscope blades, they found nearly similar median segmental movement from $\mathrm{C} 0$ to $\mathrm{C} 3$ between both

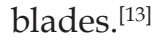

\section{Studies involving video laryngoscopes}

Robitaille et al. compared cervical spine motion in the intact cervical spine during direct laryngoscopy and Glidescope video laryngoscopy. They failed to show any difference in average C-spine movement between either technique which basically refuted the supposition that direct line of sight offered by video laryngoscopes between the operator's eye and the glottis would reduce C-spine motion during laryngoscopy. ${ }^{[14]}$ This study demonstrated majority extension at the atlanto-occipital junction as the major movement during intubation, and interestingly, they found a higher degree of movement at each cervical level than was previously demonstrated. Assessment of cervical spine motion during endotracheal intubation with lighted stylet, Glidescope and Macintosh laryngoscope was conducted by Turkstra et al. wherein cervical spine movement during endotracheal intubation was recorded using continuous lateral fluoroscopy in healthy patients who had their head rested in a neutral position in a Mayfield horseshoe ${ }^{[15]}$ In addition to cervical spine motion being decreased by $50 \%$ from C2-C5 for the Glidescope versus the Macintosh laryngoscope, they also found an average of $57 \%$ less C-spine movement with the use of Lightwand vis-a-vis the Macintosh laryngoscope at almost every cervical spine segment. Significantly, this study also proved that intubation produces more cervical spine movement than either jaw thrust or bag-mask ventilation. Maruyama et al. studied the differences in cervical spine movement when using the AirWay Scope, McCoy laryngoscope and the Macintosh laryngoscope as measured by fluoroscopy. ${ }^{[16]}$ The AirWay Scope is a 
rigid, preformed video laryngoscope that fits into the oropharynx and is advanced into the posterior pharynx along the midline until the glottis opening is observed on the liquid crystal device monitor. The AirWay Scope produced the least combined cervical spine motion followed by the Macintosh laryngoscope with maximal movement exhibited by the McCoy blade; however, the difference between Macintosh versus McCoy groups was not statistically significant. The same authors went on to repeat the previous study with the addition of MILS, excluding McCoy laryngoscopy and exhibited remarkably lesser cervical spine movement with an AirWay Scope when compared to the Macintosh blade. ${ }^{[17]}$

\section{Studies involving intubating laryngeal mask airway}

Sahin et al. compared cervical spine motion with the aid of a C-arm fluoroscopy device during intubation from neutral position amongst the Macintosh \#3 blade, intubating laryngeal mask airway (ILMA) and fibre-optic laryngoscopy in a randomised trial. ${ }^{[18]}$ Analysis revealed the least cervical spine motion being produced within the nasal fibre-optic intubation group followed by the ILMA with the maximum cervical spine movement by direct laryngoscopy using the Macintosh \#3 blade. Waltl et al. calculated cervical spine movement during intubation with the Macintosh blade and the ILMA, in which the patients were subjected to cervical spine radiographs at three different positions, namely, neutral position, maximal movement of the cervical spine and lastly after intubation. ${ }^{[19]}$ The point of maximal movement of the cervical spine in the Macintosh laryngoscopy group was deemed to be when the best possible view of the larynx was noted, and in the ILMA group, the radiograph was obtained when the intubating mask reached the posterior pharyngeal wall and the rigid, anatomically curved tube moved from the dorsal to caudal direction. Analysis revealed that the 'angle of cervical spine extension during intubation with the ILMA (Fastrach) was significantly less when compared with intubation with direct laryngoscopy in C1-C2.' While the method of measurement of cervical spine motion in the aforementioned study could be argued to be simple to perform and hence easily replicable the fact that cervical spine motion was measured at preset time points is a veritable limitation to this study in view of the fact that airway movements during intubation are a dynamic process. Kihara et al. compared cervical spine movement during intubation with the ILMA and Lightwand while maintaining MILS. ${ }^{[20]}$ Their study established that the majority of cervical spine movement during intubation was seen at $\mathrm{C}_{0-3}$ which was in agreement to the findings of previous studies such as those by Sawin et al., however, they noted $50 \%$ less cervical spine movement than was documented in the Sawin et al. study. ${ }^{[9]}$ An explanation for this discrepancy is that Sawin et al. were measuring the degree of cervical spine movement during direct laryngoscopy, which would expectedly produce more movement.

\section{Studies involving flexible bronchoscopes}

Houde et al. compared cervical spine motion following intubation with either a Trachlight or a flexible fibre-optic bronchoscope. ${ }^{[21]}$ This study found no significant difference in the degrees of movement between the two intubation techniques; however, they did note that most movement occurred during introduction of the flexible FB. Wong et al. compared cervical spine motion during flexible bronchoscopy as compared to Lo-Pro Glidescope. ${ }^{[22]}$ They demonstrated that the Lo-Pro Glidescope results in more extension as compared with the fibre-optic bronchoscope at all cervical spine levels. While this was along expected lines, the study was unique for implicating airway manoeuvres performed before FB, especially jaw thrust, with discernible cervical spine movement. ${ }^{[22]}$ The authors also noted that the flexible bronchoscopes inability to increase the posterior pharyngeal space during intubation, like a laryngoscope device would, may pose a disadvantage this intubation technique, and hence, the ability of the flexible bronchoscope to produce a small degree of cervical spine motion is a benefit only as long as access to the airway is not hindered.

\section{Studies involving other intubation aids}

There have been studies on cervical spine motion with other devices facilitating intubation. Most notable of these is the Airtraq which is an optical laryngoscope having a viewfinder, hence obliterating the requirement of a direct line of sight. Hirabayashi et al. compared cervical spine motion by an Airtraq to that produced by a Macintosh blade. They found significantly lesser movement at the upper cervical spine when intubation was achieved with an Airtraq. ${ }^{[23]}$ Turkstra et al. replicated the same findings in an independent study, only this study was better designed in view of using continuous cinefluoroscopy to capture maximal motion rather than X-rays at predefined time points. ${ }^{[15]}$ A study comparing cervical spine movements amongst Shikani Optical Stylet ${ }^{\circledR}$ and Macintosh laryngoscopy exhibited lesser movements with the stylet. ${ }^{[2]}$ A similar study comparing Macintosh laryngoscope with Bonfils intubation fibrescope showed the stylet in a favourable light. ${ }^{[25]}$

\section{SUMMARY OF REVIEW OF LITERATURE}

Hence, a thorough perusal of existing evidence from various studies pertaining to movement at the cervical spine with various intubation devices presents to us the following facts:

- Direct laryngoscopy has been shown to produce the most extension at the atlanto-occipital joint with the 
Macintosh blade producing more extension than the Miller blade ${ }^{[4,10,14,15]}$

- Face mask, chin lift and jaw thrust have been found to produce equal to greater cervical movement than the actual process of direct laryngoscopy itself $f^{[5,7,8]}$

- A theoretical advantage of video laryngoscopes concerning cervical spine motion during endotracheal intubation seems to be the obliteration of the need of a direct line of sight required during direct laryngoscopy which would result in lesser amount of force required for sighting of glottic structures, thereby resulting in lesser movement at the cervical spine. The Airway scope, Glidescope and its variant the low profile Glidescope are the video laryngoscopes studied in literature in relation to the movement at the cervical spine, and the low profile Glidescope has been found to produce the least amount of movement comparable to the movement demonstrated with a fibre-optic scope $^{[11,15,17,21,22]}$

- The ILMA, lighted stylets such as Lightwand, Bonfils fiberscope and Shikani optical stylet as well as optical laryngoscopes such as Airtraq have also been explored in terms of cervical spine excursion and found to cause less extension at $\mathrm{C} 1-\mathrm{C} 2$ and $\mathrm{C} 2-\mathrm{C} 3$ than intubation by direct laryngoscopy. ${ }^{[15,19,24,25]}$

\section{CONCLUSION}

The assumption of lesser cervical spine movements resulting in avoidance of neurological deterioration is a theoretical premise based on a substantial body of evidence of poor neurological outcomes following intubation. This has eventually led to cervical spine motion during intubation evolving as a novel field of anaesthesia research. Craniocervical motion has been quantified for various intubation aids ranging from classical laryngoscopes, various forms of stylets, video laryngoscopes and fibre-optic devices. Amongst the available devices, the fibre-optic bronchoscope, low profile Glidescope and the Lightwand have been found to produce least cervical spine motion. Simultaneously, the upper cervical spine (occiput-C4) remains the area of interest as it exhibits area of maximal movement with significant neural implications. The use of these devices in cervical spine-injured patients for securing the airway also has to consider factors such as availability, expertise and familiarity with such instruments and the feasibility of use of such devices in the emergency department scenarios. The quest for the intubation device producing the most favourable effect on cervical spine kinetics is an ongoing search and will hopefully direct further research into the hitherto unanswered questions of this fascinating clinical conundrum - how do we secure the airway in cervical spine-injured patients without causing further damage?

\section{Financial support and sponsorship} Nil.

\section{Conflicts of interest}

There are no conflicts of interest.

\section{REFERENCES}

1. Divatia JV, Bhowmick K. Complications of endotracheal intubation and other away management procedures. Indian J Anaesth 2005;49:308-18.

2. Powell RM, Heath KJ. Quadraplegia in a patient with an undiagnosed odontoid peg fracture. The importance of cervical spine immobilisation in patients with head injuries. J R Army Med Corps 1996;142:79-81.

3. Levi AD, Hurlbert RJ, Anderson P, Fehlings M, Rampersaud R, Massicotte EM, et al. Neurologic deterioration secondary to unrecognized spinal instability following trauma - A multicenter study. Spine (Phila Pa 1976) 2006;31:451-8.

4. Lennarson PJ, Smith D, Todd MM, Carras D, Sawin PD, Brayton J, et al. Segmental cervical spine motion during orotracheal intubation of the intact and injured spine with and without external stabilization. J Neurosurg 2000;92 2 Suppl: 201-6.

5. Lennarson PJ, Smith DW, Sawin PD, Todd MM, Sato Y, Traynelis VC. Cervical spinal motion during intubation: Efficacy of stabilization maneuvers in the setting of complete segmental instability. J Neurosurg 2001;94 2 Suppl: 265-70.

6. Gerling MC, Davis DP, Hamilton RS, Morris GF, Vilke GM, Garfin SR, et al. Effects of cervical spine immobilization technique and laryngoscope blade selection on an unstable cervical spine in a cadaver model of intubation. Ann Emerg Med 2000;36:293-300.

7. Donaldson WF $3^{\text {rd }}$, Towers JD, Doctor A, Brand A, Donaldson VP. A methodology to evaluate motion of the unstable spine during intubation techniques. Spine (Phila Pa 1976) $1993 ; 18: 2020-3$.

8. Donaldson WF $3^{\text {rd }}$, Heil BV, Donaldson VP, Silvaggio VJ. The effect of airway maneuvers on the unstable C1-C2 segment. A cadaver study. Spine (Phila Pa 1976) 1997;22:1215-8.

9. Sawin PD, Todd MM, Traynelis VC, Farrell SB, Nader A, Sato Y, et al. Cervical spine motion with direct laryngoscopy and orotracheal intubation. An in vivo cinefluoroscopic study of subjects without cervical abnormality. Anesthesiology 1996;85:26-36.

10. LeGrand SA, Hindman BJ, Dexter F, Weeks JB, Todd MM. Craniocervical motion during direct laryngoscopy and orotracheal intubation with the Macintosh and Miller blades: An in vivo cinefluoroscopic study. Anesthesiology 2007;107:884-91.

11. Hastings RH, Wood PR. Head extension and laryngeal view during laryngoscopy with cervical spine stabilization maneuvers. Anesthesiology 1994;80:825-31.

12. Hastings RH, Vigil AC, Hanna R, Yang BY, Sartoris DJ. Cervical spine movement during laryngoscopy with the Bullard, Macintosh, and Miller laryngoscopes. Anesthesiology 1995;82:859-69.

13. Maclntyre PA, McLeod AD, Hurley R, Peacock C. Cervical spine movements during laryngoscopy. Comparison of the Macintosh and McCoy laryngoscope blades. Anaesthesia 1999;54:413-8.

14. Robitaille A, Williams SR, Tremblay MH, Guilbert F, Thériault $M$, Drolet $P$. Cervical spine motion during tracheal intubation with manual in-line stabilization: Direct laryngoscopy versus GlideScope videolaryngoscopy. Anesth Analg 2008;106:935-41. 
15. Turkstra TP, Pelz DM, Jones PM. Cervical spine motion: A fluoroscopic comparison of the Airtraq laryngoscope versus the Macintosh laryngoscope. Anesthesiology 2009;111:97-101.

16. Maruyama K, Yamada T, Kawakami R, Kamata T, Yokochi M, Hara K. Upper cervical spine movement during intubation: Fluoroscopic comparison of the Airway scope, McCoy laryngoscope, and Macintosh laryngoscope. $\mathrm{Br} \mathrm{J}$ Anaesth 2008;100:120-4.

17. Maruyama K, Yamada T, Kawakami R, Hara K. Randomized cross-over comparison of cervical-spine motion with the Airway scope or Macintosh laryngoscope with in-line stabilization: A video-fluoroscopic study. $\mathrm{Br} \mathrm{J}$ Anaesth 2008;101:563-7.

18. Sahin A, Salman MA, Erden IA, Aypar U. Upper cervical vertebrae movement during intubating laryngeal mask, fibreoptic and direct laryngoscopy: A video-fluoroscopic study. Eur J Anaesthesiol 2004;21:819-23.

19. Waltl B, Melischek M, Schuschnig C, Kabon B, Erlacher W, Nasel $\mathrm{C}$, et al. Tracheal intubation and cervical spine excursion: Direct laryngoscopy vs. intubating laryngeal mask. Anaesthesia 2001;56:221-6.

20. Kihara S, Watanabe S, Brimacombe J, Taguchi N, Yaguchi Y,
Yamasaki Y. Segmental cervical spine movement with the intubating laryngeal mask during manual in-line stabilization in patients with cervical pathology undergoing cervical spine surgery. Anesth Analg 2000;91:195-200.

21. Houde BJ, Williams SR, Cadrin-Chênevert A, Guilbert F, Drolet P. A comparison of cervical spine motion during orotracheal intubation with the trachlight or the flexible fiberoptic bronchoscope. Anesth Analg 2009;108:1638-43.

22. Wong DM, Prabhu A, Chakraborty S, Tan G, Massicotte EM, Cooper R. Cervical spine motion during flexible bronchoscopy compared with the Lo-Pro GlideScope. $\mathrm{Br} \mathrm{J}$ Anaesth 2009;102:424-30.

23. Hirabayashi Y, Fujita A, Seo N, Sugimoto H. A comparison of cervical spine movement during laryngoscopy using the Airtraq or Macintosh laryngoscopes. Anaesthesia 2008;63:635-40.

24. Turkstra TP, Pelz DM, Shaikh AA, Craen RA. Cervical spine motion: A fluoroscopic comparison of Shikani Optical Stylet ${ }^{\circledR}$ vs. Macintosh laryngoscope. Can J Anaesth 2007;54:441-7.

25. Rudolph C, Schneider JP, Wallenborn J, Schaffranietz L. Movement of the upper cervical spine during laryngoscopy: A comparison of the Bonfils intubation fibrescope and the Macintosh laryngoscope. Anaesthesia 2005;60:668-72. 